\title{
MIGRAÇÃO E POLÍTICA: ESTRATÉGIAS COLETIVAS DOS ÍNDIOS DE CIMBRES (Pernambuco, 1820-1830) ${ }^{1}$
}

\author{
MARIANA ALBUQUERQUE DANTAS²
}

\begin{abstract}
RESUMO
0 presente artigo tem 0 objetivo de analisar as estratégias articuladas pelos indígenas de Cimbres, Pernambuco, durante as décadas de 1820 e 1830, para manter as terras coletivas de seu aldeamento e para defender a melhor forma de administrá-las. Escreveram petições, participaram ativamente da política e, nos momentos de violência aguda, migravam para uma localidade específica de Alagoas. Conseguiram, dessa forma, organizar-se e ver alguns de seus pleitos atendidos. Pretende-se, assim, compreender os fluxos e caminhos trilhados pelos indígenas de Cimbres para a reelaboração de sua identidade, bem como propor uma perspectiva sobre a História do Brasil imperial que leve em consideração diferentes sujeitos históricos.
\end{abstract}

\section{PALAVRAS-CHAVE}

Indígenas de Cimbres; Estratégias; Aldeamento; Brasil imperial.

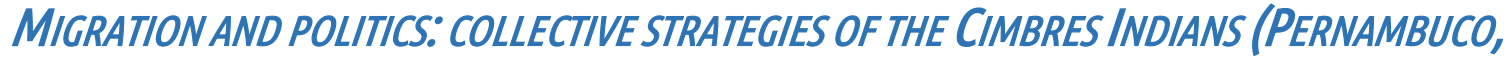 1820-1830)}

\section{ABSTRACT}

This article has as its aims analyzing the strategies developed by the indigenous people from Cimbres, Pernambuco, during the 1820 and the 1830, in order to keep the collective lands of their "aldeamento" and to assert their ways as a better form of management of those lands. They wrote petitions, dynamically engaged in political action, and, in moments of severe violence, they migrated to a particular place in Alagoas. In that way, they managed to organize themselves and to get some of their pleas fulfilled. My intention here, thus, is to understand the paths trailed by the Cimbres indigenous people and their movement flows in order to conceptually rework their identities, as well as to propose a renovated perspective about the Brazilian Imperial History that takes into account different historical subjects.

\section{KEYWORDS}

Cimbres indigenous people; Strategies; Aldeamento; Brazilian Empire.

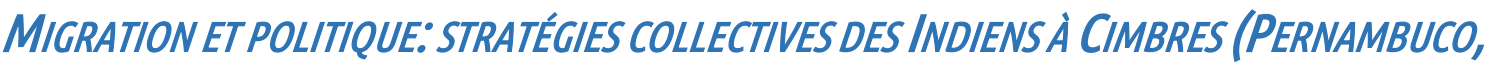 1820-1830)}

\begin{abstract}
RÉSUMÈ
Cet article vise à analyser les stratégies articulées par les peuples indigènes de Cimbres, Pernambuco, au cours des années 1820 et 1830, pour maintenir les terres collectives de leur aldeamento et défendre la meilleure façon de les gérer. Ils ont rédigé des pétitions, participé activement à la vie politique et, en période de violence aiguë, ont migré vers un endroit spécifique à Alagoas. De cette manière, ils ont réussi à s'organiser et à voir certaines de leurs revendications traitées. Il s'agit donc de comprendre les flux et les chemins suivis par les
\end{abstract}

\footnotetext{
${ }^{1}$ Agradeço a leitura atenta de Karina Melo (UPE).

2 Professora do Departamento de História e do Programa de Pós-Graduação em História da Universidade Federal Rural de Pernambuco.
} 
peuples indigènes de Cimbres pour la réélaboration de leur identité, ainsi que de proposer une perspective sur l'Histoire du Brésil impérial qui prend en compte différents sujets historiques.

\section{MOTS-CLÉS}

Indiens de Cimbres; Stratégies; Aldeamento; Brésil impérial.

\section{MiGRACIÓN Y POLITIICA: ESTRATEGIAS COLECTIVAS de LOS INDIOS de CIMBRES (PERNAMBUCO, 1820-1830)}

\section{RESUMEN}

Este artículo tiene como objetivo analizar las estrategias articuladas por los indios de Cimbres, Pernambuco, durante las décadas de 1820 y 1830, para mantener las tierras colectivas de su aldeamento y defender la mejor manera de administrarlas. Escribieron peticiones, participaron activamente en la política y, en tiempos de violencia aguda, emigraron a un lugar específico en Alagoas. De esta manera, lograron organizarse y ver algunas de sus demandas respondidas. Se pretende, por lo tanto, comprender los flujos y caminos seguidos por los indígenas de Cimbres para la reelaboración de su identidad, así como proponer una perspectiva sobre la historia del Brasil imperial que tenga en cuenta diferentes sujetos históricos.

PALABRAS CLAVES

Indígenas de Cimbres; Estrategias; Aldeamento; Brasil imperial. 
Durante as décadas de 1820 e 1830, os índios de Cimbres, como eram conhecidos, participaram intensamente da vida política local, acionando estratégias para garantir a manutenção de suas terras coletivas e a melhor forma de administrá-las. Situados na região atualmente conhecida como agreste, em Pernambuco, posicionaram-se durante a atuação das Juntas Governativas na província, processo desencadeado pelas implicações da Revolução Liberal do Porto nos anos 1820. E, posteriormente, criticaram a independência do Brasil, defendendo a volta de D. João VI. Tais escolhas políticas em face dos processos políticos regional e que envolviam as relações entre Portugal e Brasil eram reflexos dos conflitos locais relacionados às terras indígenas e também à disposição da força de trabalho e militar dos índios de Cimbres.

O objetivo desse artigo é investigar as estratégias criadas pelos índios de Cimbres relacionadas aos contextos fundiário e político local e nacional, que consistiam na escrita de petições a autoridades, na migração para Alagoas sempre que ameaças e violências eram impostas ao grupo, constituindo um fluxo de pessoas entre as duas províncias, bem como no enfretamento através de documentos e de resistência armada, quando entendiam ser necessário reafirmar seus posicionamentos abertamente.

Esse estudo se baseia em análise de documentação manuscrita disponível no Arquivo Público Estadual Jordão Emerenciano (Apeje), de Pernambuco, e no Arquivo Nacional no Rio de Janeiro (AN) através de pressupostos metodológicos da microhistória, fazendo uso principalmente das noções de estratégia, contexto e jogos de escalas, tal como definiram Jacques Revel (1998) e Giovani Levi (2000). Dessa forma, a opção metodológica se dá pelo diálogo entre os campos da História e da Antropologia política, nos termos de João Pacheco de Oliveira (2016, p. 221), que leva em consideração aspectos políticos, econômicos, sociais e culturais para compreender a formação e reelaboração de identidades étnicas em sua relação com um território específico. Tomando esse ponto de partida, as coletividades podem ser compreendidas em suas estratégias de ação em uma escala local articulando a defesa de seus interesses com outros grupos ou sujeitos históricos por meio de negociações ou conflitos armados. O nível micro, no entanto, não está desprovido de conexões com processos e jogos políticos que se processam em escalas mais amplas, em verdade faz parte deles através de imbricadas redes de relações entre sujeitos históricos em diferentes situações. Assim, acreditamos ser possível conectar as diversas modalidades de reivindicação e participação política de indígenas aos processos mais amplos de formação do Estado brasileiro no Oitocentos.

No período aqui analisado, é possível acompanhar o deslocamento dos índios de Cimbres entre Pernambuco e Alagoas como um movimento regular e de fluxo de pessoas que, além de se manifestar como estratégia, também impulsionou a reconfiguração de culturas, identidades e das relações com o território. Ainda que tenham mantido uma 
conexão profunda com o território em Pernambuco, eles atualizaram uma relação com um espaço em Alagoas ao longo da década de 1820, que já existia desde o final do século XVIII, como apontam estudos sobre o grupo Xukuru-Kariri de Palmeira dos Índios (PEIXOTO, 2013). O movimento migratório entre Pernambuco e Alagoas realizado pelos índios de Cimbres constitui, então, importante elemento da formação de sua identidade coletiva.

O posicionamento político desses indígenas na década de 1820 pode ser entendido como mecanismo semelhante nesse processo. Ao fazerem um levante a favor de d. João VI, foram descritos pelas fontes da época como indivíduos "por natureza fanáticos realistas absolutos"3. Também foram identificados como "contrários à causa do Brasil", ou seja, avessos à independência de Portugal, e contrários também à Constituição de 1824. Analisando de maneira crítica as classificações impostas pelas pessoas que produziram os documentos, é necessário compreender que, apoiando-se em pressupostos conservadores diante dos processos políticos vivenciados no Brasil, os índios de Cimbres reelaboraram sua identidade coletiva.

\section{OS ÍNDIOS QUE LEVANTARAM 0 “ESTANDARTE DE D. JoÃo VI”}

O ano de 1824 foi particularmente difícil para os índios de Cimbres, pois foram objeto de uma devassa, além de sofrerem a repressão ao movimento que realizaram a favor de d. João VI e contra o governo rebelde instaurado em Pernambuco no período.

A devassa foi instaurada para apurar a "culpa dos índios" sobre roubos nas casas e nas estradas e, ao mesmo tempo, se eram pessoas "inimigas da causa da independência do Brasil, correndo com palavras de sedução dos povos." ${ }^{4}$ A devassa foi conduzida pelo tenentecoronel Domingos de Souza Leão, sendo tomados os testemunhos de onze pessoas. Todas as testemunhas relataram os mesmos acontecimentos, diferindo em poucos detalhes uns relatos dos outros. De maneira geral afirmaram que alguns índios seriam recorrentes "ladrões de gado e dinheiro", citando-os nominalmente: José Caixeiro, Geraldo de tal, seu irmão José de tal, José de tal irmão de Félix da Costa, Antônio dos Santos, João José e João Barbosa, Pedro José Rodrigues, Vicente Cabeludo. Estes quatro últimos foram presos, mas teriam conseguido fugir do cárcere.

Além do "furto de gados", as testemunhas fizeram considerações mais gerais sobre o posicionamento político dos indígenas naquele momento, indicando, inclusive, quais seriam os responsáveis por iniciar os problemas na região. Duas das testemunhas afirmaram

\footnotetext{
${ }^{3}$ Apeje. JO2. 12/03/1824. Carta de Domingos de Souza Leão, juiz ordinário da vila de Cimbres, para o presidente da província, Manoel de Carvalho Paes de Andrade. Fl.98-99.

${ }^{4}$ Apeje. JO 2. Devassa sobre a culpa dos índios da vila de Cimbres (contra Vicente Cabeludo e outros.) Devassa iniciada 9 de janeiro de 1824 e finalizada em 19 de março de 1824. Fl.100-109.
} 
que os índios dão vivas a D. João VI e que isso prova não adotarem a causa da Independência do Brasil. Outras três reafirmaram que eles só querem o rei português e que "não querem saber de Constituição". Os índios de Cimbres eram "contrários à nossa causa do Brasil" e "com isto provam serem nossos inimigos". Este movimento, segundo as testemunhas, foi encabeçado por três capitães indígenas, Manoel da Cruz, Manoel Batista e Bento Rodrigues. Além disso, as testemunhas informaram que o capitão-mor dos índios, Manoel José, não fora aceito na aldeia por ter sido empossado pelo governo provisório de 1824. A conclusão da devassa foi a de que todos os índios citados deveriam ser presos 5 .

As acusações das testemunhas da devassa dão pistas para tentar compreender como esse grupo de índios citados entendiam os novos contextos políticos provincial e nacional e como se colocavam diante destes. O Governo Provisório ao qual o documento se refere foi o instaurado em dezembro de 1823 com a renúncia do então presidente Francisco Paes Barreto. A devassa do tenente-coronel Domingos de Souza Leão foi realizada durante o período anterior à Confederação do Equador, que foi proclamada em 2 de julho de 1824, mas num período em que a presidência da província já estava nas mãos dos rebeldes.

Nesse momento, os índios de Cimbres se mostraram contrários ao Governo Provisório dos rebeldes, uma vez que não aceitaram o capitão-mor Manoel José que fora indicado naquela situação. E também eram contrários à Independência e ao governo de D. Pedro I, opondo-se à Constituição e desejando a volta de D. João VI. Ou seja, em meados de 1824, aquele grupo indígena se posicionou contrariamente ao governo centralizado na corte no Rio de Janeiro, bem como aos seus adversários políticos em Pernambuco.

É importante ressaltar que esta situação estava imbricada às desavenças entre políticos locais e fica mais evidente com a atuação dos índios João José, Vicente Cabeludo e João Barbosa citados na devassa de 1824. Tal como fizera Bento Rodrigues, esses índios se opuseram "à primeira eleição paroquial para a nomeação de deputados às cortes em Portugal" ocorrida em Cimbres, "protestando somente defender o seu rei Dom João VI a quem ainda hoje exclusivamente são adictos"6. De acordo com Domingos de Souza Leão, o mesmo autor da devassa que também era Juiz Ordinário, os índios

\footnotetext{
"são por natureza fanáticos realistas absolutos [...] porque a sua ferocidade filha da mesma estupidez exaltada diariamente pela fácil embriagues, a licença e impunidade em que vivem fazem desanimar a qualquer patriota que os pretenda caridosamente iluminar ${ }^{7 \prime}$.
}

\footnotetext{
5 Idem.

${ }^{6}$ Apeje. JO2. 12/03/1824. Carta de Domingos de Souza Leão, juiz ordinário da vila de Cimbres, para o presidente da província, Manoel de Carvalho Paes de Andrade. Fl.98-99.

${ }^{7}$ Idem.
} 
O capitão-mor das Ordenanças da vila de Cimbres, Manoel José de Serqueira, também deu o seu parecer sobre os índios, ressaltando os crimes que teriam cometido, afirmando que "seu sistema é roubar". O capitão-mor esperava a pronta obediência dos índios diante de suas ordens, como ocorreu em 1817, quando foi feito o recrutamento de cem índios para compor as tropas de repressão à Revolução Pernambucana. Mas, ao contrário, percebeu que não podia contar com eles pois, mesmo que se ponham a marchar, "formam entre eles uma desconfiança, daí voltam roubando, desolando tudo, a fim de acharem a terra destituída de homens, para se apoderarem das famílias". Ainda em 1824, informou que chegaram cerca de cem índios de Palmeira (Alagoas) e que estariam esperando o momento do ataque, já que continuavam realizando furtos ${ }^{8}$ (CARVALHO, 1996, p. 60).

A atuação deste capitão-mor de Cimbres é crucial para compreender o comportamento político dos indígenas envolvidos nas disputas locais. Após a devassa empreendida em 1824, o capitão-mor, Manoel José de Serqueira tentou realizar um recrutamento forçado na aldeia do Ararobá de cerca de 300 índios, no intuito de corresponder a um pedido do tenente coronel Manoel Ignacio Bezerra de Mello, de auxílio para o Exército. Serqueira enviou uma solicitação ao capitão-mor dos índios, repassando o pedido. O capitão-mor dos índios, por sua vez, respondeu informando que "não dava a sua gente por respeito de um, não haviam de ir tantas almas para os reinos dos infernos" ${ }^{\prime 9}$.

A negativa audaciosa do capitão-mor dos índios, sobre o qual não temos mais informações, não foi retrucada imediatamente, mas quase um mês depois quando Serqueira soube que os índios haviam içado "o estandarte de João sexto". Por já esperar essa reação, Serqueira pediu auxílio a tropas de companhias vizinhas, que fizeram patrulhas nas estradas até chegar na vila de Cimbres e enfrentar os índios. De sua tropa, segundo ele, não houve muitas baixas. Já do lado dos índios, muitos morreram, embora não se saiba seu número exato, porque vários foram morrer nos matos. Estima, no entanto, cerca de 20 mortos. Informa que prendeu 60 indígenas, em sua maioria casados, e outros 25 foram recrutados, sendo estes solteiros. Entre presos e recrutados, totalizou 85 índios ${ }^{10}$.

Na lista dos indígenas presos figuram Manoel Vieira da Cruz, provavelmente o mesmo que encabeçava movimentos favoráveis a D. João VI relatados na devassa já citada, e Antônio dos Santos, acusado na mesma devassa de "roubar gado" e fugir da prisão. Outros 32 índios se renderam e chegaram ao quartel de Serqueira, que os teria prendido se tivesse

\footnotetext{
${ }^{8}$ Apeje. Ord. 3. 28/04/1824. Ofício do capitão mor de Cimbres, Manoel José de Serqueira, para o presidente da província, Manoel de Carvalho Paes de Andrade. fl.332-332v.

${ }^{9}$ Apeje. Ord.3. 27/06/1824. Ofício do capitão mor e diretor de Cimbres, Manoel José de Serqueira, ao presidente da província, Manoel de Carvalho Paes de Andrade. fl.364-365v.

${ }^{10}$ Idem.
} 
oportunidade pois "ladrões e revolucionários todos são". Além destes, dois capitães dos índios também foram presos ${ }^{11}$.

A tentativa violenta de recrutamento empreendida por Manoel José de Serqueira e o consequente enfrentamento com os índios, resultando em mortes, fugas e prisões, podem ser compreendidos como ações repressivas em relação ao posicionamento político dos indígenas. Esvaziar a aldeia e recrutar através de prisões levaria a uma desmobilização na aldeia de grande parte de sua população masculina. A ação de Serqueira teve, então dois objetivos: angariar braços para suas tropas e esvaziar a aldeia.

Diante do exposto, acreditamos ser esse o episódio sobre o qual historiadores da região trataram como massacre. (BARBALHO, 1984, p. 34-35; COSTA, 2004, p. 241) Apesar de as fontes da época não relatarem da mesma forma que Nelson Barbalho e Pereira da Costa, a violência exercida pelo representante em Cimbres do governo rebelado da província, os fatos relacionados ao episódio e o número de índios presos e recrutados nos leva a concluir que Manoel José de Serqueira foi o responsável pela repressão ao levante dos indígenas. Por outro lado, a resistência de cerca de 300 indígenas ao recrutamento forçado indica uma relação conflituosa entre Serqueira e os índios de Cimbres, provavelmente marcada pela experiência de 1817 e de anos posteriores.

Cabe agora o questionamento sobre as motivações e expectativas indígenas na configuração de seus apoios e suas rivalidades políticas em 1824. O posicionamento político indígena foi construído inserido num quadro complexo de disputas locais pelas terras do aldeamento e por cargos políticos, que ganharam novos significados com o contexto institucional e político delineado entre os anos de 1820 e 1822 e com a eclosão da Confederação do Equador em 1824.

\section{ATUAÇÃO POLÍTICA DOS ÍNDIOS DE CIMBRES E TENTATIVA DE EXTINÇÃO DO ALDEAMENTO}

No ano de 1822 os antagonismos entre índios de Cimbres e autoridades locais se intensificaram frente à discordância dos primeiros em relação ao capitão-mor eleito pela Câmara Municipal para os administrar e à possibilidade de extinção do aldeamento. Nesse ano, os índios de Cimbres, representados por seus capitães, alferes, outros oficiais e soldados, enviaram uma petição à Junta do Governo de Pernambuco solicitando a restituição de seu antigo capitão-mor, Alexandre Pereira da Costa, ao cargo, pois não reconheciam o seu substituto, Francisco Alves Feitosa. Em sua argumentação, afirmaram que tal posto competia

\footnotetext{
${ }^{11}$ Idem.
} 
verdadeiramente a Costa, embora este tenha pedido demissão. Costa havia se demitido do cargo alegando que já estava em idade avançada ${ }^{12}$.

Na perspectiva dos índios que fizeram a petição, a Feitosa faltava idoneidade e o conhecimento da língua para saber ler e escrever e assim "guardar os segredos necessários da Junta Governativa". Além disso, ele não era "verdadeiramente índio". Segundo os indígenas, para assumir tal cargo era necessário observar o que determinava o Diretório, ${ }^{13}$ ainda em vigor na província, sendo o indivíduo encarregado do cargo "um homem instruído, amante da nação, que só tenha em vista o bem geral de todos os cidadãos" e também sendo obediente às cortes. Relembram que, de acordo com o Diretório, era preciso que o Ouvidor da Comarca chamasse todos os índios à sua presença para eleger o capitão-mor pela "maioria de vozes", sendo assim um indivíduo escolhido diretamente pelos indígenas. A petição foi assinada por quatro capitães e outro indígena sem patente militar. ${ }^{14}$ Destes indígenas, dois foram presos em 1824 após resistir à tentativa de recrutamento forçado de Manoel José de Serqueira: os capitães Joaquim Pereira da Costa e Leonardo Francisco da Silva. E um terceiro capitão indígena, Bento Rodrigues de Mendonça, que também assinou essa petição, foi acusado na devassa de 1824 de encabeçar o movimento na vila a favor de D. João VI.

Ao defender um indivíduo para o cargo de capitão-mor, os indígenas suplicantes demonstraram seu interesse em interferir diretamente na maneira pela qual eram administrados, requerendo para isso uma pessoa que fosse "verdadeiramente índio" e que, por isso, deveria compreender as suas necessidades. Ao contrário do que algumas autoridades alegaram em 1824, descrevendo os índios de Cimbres como simples "fanáticos realistas absolutos", da petição pode-se perceber que as escolhas políticas indígenas eram

${ }^{12}$ Apeje. CM 3. 14/03/1822. Ofício da Câmara da vila de Cimbres ao Governo da Junta Provisória de Pernambuco. Fl.317.

${ }^{13}$ A fonte faz referência ao Diretório dos Índios de 1757, que fez parte da política do Marquês de Pombal de reenquadramento do Império português no contexto internacional, tendo sido elaborado para a realidade do Estado do Grão-Pará e Maranhão. Foi extinto nessa região em 1798 e apenas em 1822, por decreto imperial, nos outros espaços que compunham o Brasil. Na capitania de Pernambuco e suas anexas foi adaptado com poucas mudanças em 1758 , recebendo o título de "Direção com que interinamente se devem regular os índios das novas vilas e lugares eretos nas aldeias da capitania de Pernambuco e suas anexas". Os dois documentos dispunham sobre mudanças que deveriam ser impostas às populações indígenas para que se tornassem vassalos do rei sem diferenças em relação aos demais, incluindo casamentos interétnicos, reformulação no traçado das aldeias e sua transformação em vilas com nomes portugueses, e o uso exclusivo da língua portuguesa. O Diretório e a Direção também instituíram a figura do diretor de aldeia, que deveria assumir a administração secular dos indígenas e dos seus bens. É a essa função que a fonte citada faz referência, tendo sido mantida nas primeiras décadas do século XIX e atualizada em 1845 com o Regulamento das Missões, instituído pelo Decreto $n^{\circ} 426$. Para maiores informações, consultar Medeiros, 2011 e Sampaio, 2009.

${ }^{14}$ Apeje. CM3. 28/04/1822. Petição de oficiais e soldados indígenas à Junta do Governo de Pernambuco sobre o provimento do cargo de capitão-mor dos índios de Cimbres. Fl.326-328. 
muito mais complexas do que é possível supor a partir de uma classificação pouco explicativa como a usada na documentação da época.

Eles utilizaram conceitos como os de "nação" e "cidadão", e também defenderam obediência às cortes, em referência às Cortes de Lisboa. Além disso, defenderam a Junta Governativa de Gervásio Pires, já que o capitão-mor dos índios de Cimbres deveria saber ler e escrever para guardar os segredos dela. Faziam, portanto, referência a um contexto político no qual estavam sendo discutidos projetos sobre a constituição do Reino Unido de Portugal, Brasil e Algarve. Em Portugal, desde a Revolução Liberal do Porto (1820) e da reunião das Cortes de Lisboa (1821), o debate político se concentrou no retorno da sua posição de destaque no quadro do Reino transatlântico, no retorno de d. João VI à antiga metrópole e na preparação de uma constituição a qual o monarca deveria jurar, mostrando-se submisso. Em Pernambuco, após a experiência da violenta repressão de 1817 e do retorno de alguns de seus líderes com a anistia de 1821, o contato com Lisboa se mostrou mais intenso por meio das disposições das cortes, inclusive a de criar juntas governativas. Além disso, a necessidade de alcançar maior autonomia política para a província parecia ser algo possível, principalmente durante o governo da Junta de Gervásio Pires. Apesar do clima de autonomia regional impulsionado pelo primeiro liberalismo português, em Pernambuco não havia a pretensão de independência política da província ou do Brasil. Até então, toda a negociação era feita com Lisboa, em detrimento do Rio de Janeiro e do governo do príncipe regente d. Pedro I. (BERNARDES, 2003, p. 228; NEVES, 2009, p. 109-110).

Portanto, em 1822 os indígenas de Cimbres que escreveram a petição estavam fazendo referência a esse contexto político de conexão entre as diferentes partes do Reino Unido, e com um horizonte de conceitos liberais, como os de nação e cidadão. Ao defender esse vínculo, tratando das cortes e da junta em seu documento, é provável que o objetivo tenha sido manter o direito de interferência na administração da aldeia, tal como vinham fazendo até o momento. Eles estavam, assim, interpretando as questões políticas em debate a partir do seu próprio ponto de vista e de seus interesses. Os indígenas estavam defendendo o regime político no qual acreditavam que poderiam manter o acesso sobre o território da aldeia e o poder de interferência sobre a sua administração. Fizeram uma mescla muito própria entre concepções diferentes, estabelecendo conexões entre ideais liberais e o mundo do Antigo Regime, no qual adquiriram seus direitos sobre as terras. Jogavam, portanto, com as questões políticas do momento para alcançar seus objetivos.

Apesar do esforço e mobilização dos indígenas de Cimbres em torno da petição, a câmara da vila elegeu Francisco Alves Feitosa para a função, indivíduo indesejado pelos 
índios ${ }^{15}$. Não satisfeitos com a eleição, alguns índios junto com o seu antigo capitão-mor, Alexandre Pereira da Costa, dirigiram-se ao Ouvidor da Comarca para queixar-se de que não reconheceriam nem obedeceriam a Feitosa. Depois de classificá-lo como "misturado índio" ou "mameluco", o Ouvidor ponderou que Feitosa, embora não fosse idôneo ou bom para o posto que the foi conferido, não deixava de ser mais digno ou melhor do que seu antecessor. No entanto, para garantir o sossego e a cultura dos índios, sugeriu que fosse feita uma eleição para o cargo, sendo escolhido um oficial de primeira linha de ações discretas, mas de "suficiente força" que se encarregaria dos índios de acordo com a Diretoria, referindo-se ao Diretório do Índios. Dessa maneira, o ouvidor entendia que o capitão-mor poderia punir os indígenas quando merecessem, e também "os compelir ao trabalho e serviço agrário e totalmente removê-los da habitual inércia e ociosidade em que estão; origem, por certo, imediata de sua geral dissolução e dominante embriaguez"16.

Durante essa disputa sobre quem deveria assumir o cargo de capitão-mor, a aldeia de Cimbres passou por um forte golpe. No mesmo ano de 1822, a Câmara Municipal tentou extinguir o aldeamento e reverter ao seu patrimônio parte das terras dos índios. O juiz presidente da câmara era Francisco Xavier Pais de Melo Barreto (COSTA, 2004, vol. 6, p. 241). Isso teria feito os índios de Cimbres se aliarem ao maior inimigo político de Melo Barreto, Manuel José de Serqueira, passando a ser apelidados de "corcundas", ou partidários da monarquia portuguesa tal como era o seu novo aliado (BARBALHO, 1984, vol. 13, p. 99). Diante dos conflitos em torno da sua administração e da possibilidade de extinção do aldeamento, a aliança entre índios e Serqueira é um indício das relações de dependência mútua entres estes agentes históricos que, no entanto, iriam variar e se transformar de acordo com as mudanças políticas de cada situação. Cabe lembrar que a aliança com Serqueira foi desfeita em 1824, quando ele mudou seu posicionamento político, passou a dar apoio ao governo rebelde em Pernambuco, e tentou recrutar os indígenas de maneira forçada.

No contexto da Confederação, os indígenas da aldeia de Cimbres estavam imersos em relações de violência, de recrutamento forçado e de tentativas de invasão de suas terras, tendo a Câmara da vila papel central nesse movimento de esbulho. Defender d. João VI e escrever petições podem ter sido atitudes assumidas como estratégias pelos indígenas para fazer frente a essa situação local de conflitos e disputas políticas.

\section{POSICIONAMENTOS POLÍTICOS FLUIDOS E DEFESA DO TERRITÓRIO}

\footnotetext{
${ }^{15}$ Apeje. CM 3. 25/06/1822. Ofício da Câmara Municipal de Cimbres ao Governo da Junta Provisória de Pernambuco. Fl.323.

${ }^{16}$ Apeje. OC 2. 19/08/1822. Ofício de Thomás Antonio Maciel Monteiro para a junta provisória do governo da província de Pernambuco. Fl.210-211.
} 
Buscar compreender os significados do posicionamento político indígena em situação de conflitos armados nos impele a perceber as mudanças em suas escolhas, construídas e reconstruídas em função das transformações vivenciadas nos cenários local, provincial e nacional. As transformações realizadas pelos indígenas em suas estratégias políticas contribuem para reafirmar as características situacional e fluida das negociações e dos embates que empreendiam, e desmontar a ideia de que seriam monarquistas e realistas por natureza. Importante exemplo sobre as transformações no posicionamento indígena é o requerimento de Bento Rodrigues, um dos líderes do levante indígena a favor de d. João VI, datado de 1825.

Em seu requerimento, Bento dirigiu-se diretamente ao presidente da província de Pernambuco e pediu providências sobre a situação em que se encontravam a aldeia e os índios, abordando dois pontos. O primeiro relativo ao ataque realizado pelas autoridades da vila sobre os índios, porque estes içaram o estandarte imperial, fazendo referência à ação de Serqueira. E o segundo sobre a necessidade de comandar sozinho os outros índios, pois o seu capitão-mor os teria desamparado desde junho de 1824. Logo em seguida, ele se queixou da sua prisão, realizada a mando de Manoel José de Serqueira, então Diretor do aldeamento e capitão-mor das Ordenanças de Cimbres. Segundo Bento Rodrigues, ele teria sido preso porque cumpriu as ordens do brigadeiro Francisco Lima e Silva, comandante das tropas imperiais e da repressão à Confederação, de prender os filhos do comandante André Cavalcanti e depois marchar para o acampamento de Inhumas ${ }^{17}$.

Ao final da correspondência tratou da possibilidade de os índios saírem da vila em decorrência dos vexames e ataques sofridos porque "todos os brancos e autoridades circunvizinhas desta vila são postos a destruir estes miseráveis índios com representações falsas". E ainda defendeu que as terras, onde os "brancos" têm roças, foram recebidas em mercê, "por ser também os índios vassalos que só querem que só exista Sua Majestade Imperial para quem estão prontos a darem as vidas tudo [sic] como aconteceu este ano próximo passado [1824]"18.

É interessante compreender o posicionamento de Bento Rodrigues nessa correspondência a favor da "Sua Majestade Imperial" e o destaque ao apoio conferido ao comandante da repressão à Confederação do Equador. Ao se colocarem, em 1824, a favor de d. João VI, que já havia voltado para Portugal e que ainda não havia reconhecido a independência do Brasil, os indígenas estavam se posicionando contra o governo de Manuel de Carvalho Paes de Andrade que tentava negociar maior autonomia provincial com d. Pedro

17 Apeje. 12/07/1825. Ord.4. Ofício do capitão dos índios de Cimbres, Bento Rodrigues de Mendonça, ao governador capitão general da província de Pernambuco. Fl.3-3v.

18 Idem. 
I. O fracasso da negociação e a outorga da constituição culminaram em Pernambuco com a eclosão da Confederação do Equador. Ao mesmo tempo, os indígenas de Cimbres, inclusive Bento Rodrigues, foram acusados na devassa de 1824 de serem contrários à Independência e à constituição, portanto, opositores ao regime político liderado por d. Pedro I.

Diante desse intrincado quadro político e com a iminência da derrota do governo rebelde, pode ter parecido mais interessante para Bento Rodrigues e outros índios ajudar na repressão desse movimento, alinhando-se às tropas de d. Pedro I, lideradas em Pernambuco pelo Brigadeiro Lima e Silva. Em julho de 1825, data da correspondência de Bento Rodrigues, com a estabilização em Pernambuco do regime político centralizado na Corte, podemos inferir que passou a ser crucial para esse líder mostrar-se como um obediente vassalo do Imperador, por quem os indígenas estavam dispostos a "darem as vidas"19. Não à toa, Bento Rodrigues destaca no requerimento a sua obediência ao Brigadeiro Lima e Silva, a sua prisão injustificada, bem como a perseguição que os indígenas estavam sofrendo e a invasão das terras das aldeias, recebidas em mercê por serem "também os índios vassalos"20.

As estratégias e escolhas indígenas poderiam se transformar de acordo com as mudanças nas condições políticas, fazendo-os se adaptarem e reelaborarem seus posicionamentos frente a diferentes circunstâncias. Mais uma vez, relacionaram o seu direito ao território coletivo adquirido no período colonial às novas condições políticas advindas com a Independência do Brasil, com um novo imperador, com as disputas entre projetos políticos de centralização do Império e de maior autonomia para as províncias.

Apesar de todo esse esforço em conseguir proteção às perseguições sofridas e em manter seu território coletivo, muitos indígenas de Cimbres saíram da aldeia após o recrutamento realizado por Serqueira e se refugiaram em Alagoas, lá se estabelecendo por alguns anos.

Levando em consideração as diferentes estratégias indígenas no intuito de dar continuidade aos seus direitos sobre as terras coletivas, o espaço do aldeamento ganha centralidade nas vivências indígenas, garantindo certo grau de autonomia aos seus habitantes para manter seus costumes e fazer frente às ações dos potentados locais. A autonomia adquirida era relativa, uma vez que os indígenas sofriam uma série de restrições em relação aos usos de parcelas das terras e à própria administração do aldeamento, que era ordenada pela legislação indigenista do período. No entanto, as frequentes demandas dos indígenas feitas no intuito de interferir nesses espaços, demonstram que tentavam

\footnotetext{
${ }^{19}$ Apeje. 12/07/1825. Ord.4. Ofício do capitão dos índios de Cimbres, Bento Rodrigues de Mendonça, ao governador capitão general da província de Pernambuco. Fl.3-3v.

20 Idem.
} 
administrá-lo de acordo com seus interesses, não sendo raro resistirem quando os viam contrariados.

Além da relativa autonomia, manter as terras coletivas poderia significar alguma proteção para os indígenas em relação aos trabalhos agrícolas em fazendas vizinhas e ao serviço militar através de recrutamentos forçados. Os indígenas foram descritos, na maioria das fontes, como vagabundos, ladrões de gado, desconfiados, nocivos a eles próprios e ao público, indolentes, de moral repreensível ${ }^{21}$ e violentos. Como afirmara o ouvidor da comarca do sertão em 1822, para as autoridades não indígenas, era necessário que os índios fossem compelidos ao trabalho e ao serviço agrário, tirando-os de sua "habitual inércia e ociosidade"22. Era necessário subordiná-los ao trabalho nas propriedades de grandes potentados locais ou na prestação de serviços militares para políticos investidos de poder de polícia que, na maioria das vezes, também eram importantes proprietários das vilas e dos povoados. Nesse contexto local, defender os aldeamentos coloniais em pleno século XIX ainda significava certo grau de proteção e acesso à terra, como bem demonstrou Maria Regina Celestino de Almeida (ALMEIDA, 2010).

\section{MIGRAÇÕES: CAMINHOS DE VOLTA PARA CIMBRES}

Em fevereiro de 1830, chegou em Cimbres grande número de índios da província de Alagoas, tendo sido chamados pelo seu diretor Antônio Francisco Cordeiro, em cuja casa se estabeleceram num primeiro momento. Chegaram armados, o que fez o Juiz de Paz da vila pedir instruções ao presidente da província sobre como deveria proceder, e também por terem sido os mesmos que em 1824 fizeram a sublevação "levantando uma bandeira portuguesa, roubando gado, lavouras e mais criações dos habitantes das circunvizinhanças desta vila". O Juiz de Paz supôs que os índios tinham chegado com a intenção de furtar para se sustentarem, já que não tinham roças nem qualquer outro gênero de primeira necessidade 23 .

Mas, os índios não tentaram voltar para Cimbres sem antes fazer um pedido formal em relação às terras em que viveram. José Gonçalves Rodrigues, que se intitulava tenente ajudante e ainda estava em Alagoas, enviou uma petição ao Imperador pedindo auxílios para voltar à vila de Cimbres,

\footnotetext{
${ }^{21}$ Apeje. OC2. 11/09/1822. Ofício do ouvidor da comarca, Thomás Antonio Maciel Monteiro, para os presidentes e membros da Junta Provisória do Governo da província de Pernambuco. Fl.249-249v.

22 Apeje. OC2. 19/08/1822. Ofício de Thomás Antonio Maciel Monteiro para a junta provisória do governo da província de Pernambuco. Fl.210-211.

${ }^{23}$ Apeje. JP 2. 26/02/1830. Ofício do juiz de paz de Cimbres, José Camelo Pessoa Cavalcante, para o presidente da província de Pernambuco, Joaquim José Pinheiro de Vasconcelos. Fl.28-28v.
} 
"porque há seis anos que estamos fora dela por causa de Manoel José de Serqueira, e mais seus agregados, que tem destruído muito os índios e as Ordenanças desta vila, é de bem que vossa majestade Imperial se digne mandar dar as providências necessárias com a sua justiça reta portanto ${ }^{24 . "}$

Diante dessa petição enviada diretamente ao Imperador, tornou-se necessário para as autoridades em Pernambuco saber quem era o suplicante. O Diretor dos índios de Cimbres informou que o índio José Gonçalves não possuía a patente com a qual se intitulava. Segundo o diretor, ele era um cabo de esquadra, de má conduta e que costumava furtar, e quando se ausentou de Cimbres em 1824 não levava nada além de seu arco e flecha. Foi relatado também um episódio em que ele teria espancado a própria esposa até a morte para juntar-se a outra mulher ${ }^{25}$.

De posse dessas informações e de outras remetidas pelo Diretor da aldeia, o presidente de Pernambuco enviou ofício ao Ministro do Império, no qual ratificou a informação de que José Gonçalves não era tenente ajudante, mas que solicitava a tomada da vila de Cimbres. O presidente afirmou também que vários índios estavam sem a posse de alguns terrenos, "que thes pertenciam por antigas Datas" ${ }^{26}$. Assim, vemos que a solicitação de José Gonçalves ao Imperador era relativa à posse pelos índios de terras que precisaram abandonar em 1824.

Alguns meses depois, outro requerimento foi enviado ao Imperador, desta vez por Manoel José Leite Barbosa, capitão-mor dos índios de Cimbres, que continuara vivendo no aldeamento. Ele reclamava não terem sido restituídas as terras que foram tomadas pelo capitão-mor Manoel José de Serqueira ${ }^{27}$. No requerimento de Manoel José Leite Barbosa, não há referências a sua identidade indígena, nem à sua atuação anterior. No entanto, inferimos que é o mesmo que não fora reconhecido pelos próprios indígenas como seu capitão-mor em 1824, por ter se aliado ao governo da Confederação ${ }^{28}$. Ou seja, ele foi um dos poucos indígenas naquela vila que apoiava o governo rebelde. Mas em 1830, a situação política em Pernambuco estava estabilizada, e os antigos líderes da Confederação passavam a agir dentro dos limites estabelecidos pela administração sediada no Rio de Janeiro. Assim,

${ }^{24}$ AN. Série Interior. *IJJ249. Março a agosto de 1830. Documentos referentes ao requerimento de José Gonçalves Rodrigues feito ao Imperador sobre a retomada de sítios pelos índios que passaram 6 anos fora de Cimbres. fl.276-279.

25 Idem.

26 Ibidem.

27 AN. Série Interior. *IJJ249. 07/10/1830. Ofício do presidente da província de Pernambuco, Joaquim José Pinheiro de Vasconcelos, para o Marquês de Caravelas. Fl.291-292.

${ }^{28}$ Apeje. JO 2 Fl.98-99. 12/03/1824. Carta de Domingos de Souza Leão, juiz ordinário da vila de Cimbres, para o presidente da província, Manoel de Carvalho Paes de Andrade. 
diante das mudanças nos contextos políticos nacional, provincial e local e também das possibilidades reais de esbulhos das terras do aldeamento da serra do Ararobá, foram rearticuladas alianças entre os próprios indígenas, fazendo-os aceitar Manoel José Leite como um de seus representantes.

Vemos, então, que antes da retomada de terras pelos indígenas ou a "tomada da vila de Cimbres" havia requerimentos de um representante indígena em Alagoas, José Gonçalves Rodrigues, e de outro que ainda estava em Cimbres, Manoel José Leite. É possível inferir que as duas lideranças indígenas em províncias diferentes estivessem articuladas para exercer maior pressão sobre as autoridades responsáveis pelo caso. Essa seria uma estratégia indígena para acelerar o processo e para que o retorno fosse feito de acordo com os seus próprios termos.

Além de Manoel José Leite e José Gonçalves Rodrigues, outra liderança indígena estava envolvida nas questões sobre terra em 1830, o índio Antônio Pedro, que em 1827 fora nomeado capitão-mor do aldeamento de Cimbres (COSTA, 2004, vol. 6, p. 242). Este capitão-mor, junto com outros índios, reivindicou as datas das terras concedidas, dirigindo-se ao presidente da província ${ }^{29}$. Nessa ocasião, os índios estavam fortemente armados e o clima de tensão havia se intensificado devido às disputas pelas terras do aldeamento.

Foi feito, então, um acordo entre o Diretor dos índios, Antônio Francisco Cordeiro de Carvalho, e o capitão-mor, Antônio Pedro, a pedido e sob as orientações do presidente da província, Joaquim José Pinheiro de Vasconcelos. Neste acordo, os índios entregaram metade dos seus armamentos e nada mais foi solicitado a eles no intuito de "não se suscitar talvez algum motim entre eles, o que poderia ser pernicioso". Foi permitido que permanecessem com a outra metade das armas, porque Antônio Pedro alegava que os índios tinham inimigos e que era necessário mantê-las para se defenderem. E assim foi acertado, pois o próprio capitão-mor dos índios apresentava bom comportamento e mantinha seus liderados quietos, de acordo com o diretor da aldeia ${ }^{30}$.

Em contrapartida à entrega dos armamentos, Antônio Pedro solicitou diretamente ao capitão-mor agregado de Cimbres Francisco Xavier Pais Mello Barreto, que fossem dirimidas quaisquer dúvidas com os moradores pois "os índios vão tomar conta dos seus sítios" ${ }^{\prime 1}$. Com essa expressão, Antônio Pedro tentava demonstrar que os índios que estavam

${ }^{29}$ AN. Série Interior. *IJJ249 01/05/1830. Documentos referentes ao requerimento do índio José Gonçalves Rodrigues feito ao Imperador sobre a retomada de sítios pelos índios que passaram 6 anos fora de Cimbres. fl.276-279.

${ }^{30}$ Apeje. Ord.8. 08/05/1830. Ofício do Diretor dos Índios de Cimbres, Antônio Francisco Cordeiro de Carvalho, ao presidente da província, Joaquim José Pinheiro de Vasconcelos. Fl.96-96v.

31 Apeje. Ord.8. 08/04/1830. Ofício do capitão-mor dos índios de Cimbres, Antônio Pedro, ao capitão-mor das Ordenanças da mesma vila, Francisco Xavier Pais Mello Barreto. Fl.102. 
em Cimbres e os que haviam chegado de Alagoas recentemente não deixariam os sítios que compunham a aldeia abandonados e transformados em capoeiras, como já se havia alegado. Mas, que tomariam a sua posse, dando-lhes uso.

Sobre os três índios que fizeram requerimentos referentes às terras indígenas em 1830, sabemos pouco além do que deixaram registrado em seus pedidos, com exceção de Manoel José Leite, cujo relacionamento com seus comandados estava documentada desde 1824. Mesmo sem ter conhecimento de suas trajetórias, sabemos que a pressão exercida pelos índios liderados por José Gonçalves Rodrigues, Antônio Pedro e Manoel José Leite, seja através de petições ou por meio da possibilidade de cometerem ações violentas, surtiu efeito, conseguindo que suas reivindicações fossem atendidas.

O presidente da província de Pernambuco decidiu reempossar os sítios aos índios ${ }^{32}$, inclusive porque já havia muitas reclamações "acerca desse negócio de terras dos índios daquela vila"33. Esta ordem foi cumprida pelo Diretor dos índios, sendo restituídos dois sítios, o das Minas e o Pedra d'Água ${ }^{34}$. Na ratificação da posse pelos índios feita pelo ouvidor da comarca do sertão, ainda foram inseridos os sítios Gaipe ou Caipe, Aflitos, Santana e Santa Catarina, sendo este último o local onde Antônio Pedro havia escrito a sua requisição (COSTA, 2004, vol. 6, p. 240).

Representados por três lideranças, os índios de Cimbres, que haviam se retirado da posse de alguns sítios do aldeamento e se refugiado em Alagoas por causa de seu posicionamento político em 1824, conseguiram reaver seus terrenos através de requerimentos, dirigidos inclusive ao Imperador, e também através de ameaça de conflitos, já que provavelmente o fato de terem voltado armados a Cimbres indica que estavam preparados e dispostos a impor alguma resistência.

A ação ou luta política na busca de satisfação de interesses comuns, como afirma Weber, é um dos elementos no processo de construção de identidades e do sentimento de comunhão étnica (WEBER, 2009). Então, na situação de conflito em torno da retomada das terras do aldeamento, pareceu fundamental para as lideranças se reunirem na defesa das demandas coletivas, reafirmando a identidade coletiva relacionada a um território muito específico. Outros elementos importantes no processo de reelaboração identitária foram o posicionamento político dos indígenas na década de 1820 e a prática migratória entre

\footnotetext{
32 AN. Série Interior. *IJJ249. 28/09/1830. Oficio do presidente da província, Joaquim José Pinheiro de Vasconcelos, ao Marquês de Caravelas. Fl.276-276v.
}

33 AN. Série Interior. *IJJ249. 07/10/1830. Ofício do presidente da província de Pernambuco, Joaquim José Pinheiro de Vasconcelos, para o Marquês de Caravelas. fl. 291-292.

${ }^{34}$ AN. Série Interior. *IJJ249. 01/05/1830. Ofício do Diretor dos Índios da vila de Cimbres, Antônio Francisco Cordeiro de Carvalho, ao Ouvidor da Comarca do Sertão, Antônio de Araújo Ferreira e Jacobina. Fl. 277-277v, 277a. 
Cimbres, em Pernambuco, e Palmeira, em Alagoas, articulada pelos indígenas que habitavam as duas regiões. Acompanhando a dinâmica local, torna-se possível compreender a dimensão política na composição dos povos indígenas como sujeitos históricos participantes ativos dos rumos construídos para o Brasil imperial na primeira metade do século XIX. Desnaturalizando classificações e julgamentos explicitados nas fontes, podemos escovar a história a contrapelo, como sugeriu Walter Benjamin (2016), e elaborar percepções mais complexas sobre a História política do Brasil no Oitocentos.

\section{REFERÊNCIAS}

ALMEIDA, Maria Regina Celestino de. Os índios na História do Brasil. Rio de Janeiro: Editora FGV, 2010.

BARBALHO, Nelson. Cronologia Pernambucana: subsídios para a história do agreste e do sertão. Volumes 11 ao 14. Recife: Centro de Estudos de História Municipal/ FIAM, 1983-1984.

BENJAMIN, Walter. 0 anjo da história. Organização e tradução de João Barrento. $2^{\text {a }}$. Ed, 1a . Reimp. Belo Horizonte: Autêntica editora, 2016.

BERNARDES, Denis. Pernambuco e o Império (1822-1824): sem constituição soberana não há união. In: JANCSÓ, Istvan (org.). Brasil: formação do Estado e da Nação. São Paulo: Hucitec; Ed. Unijuí, Fapesp. 2003. p. 219-250.

CARVALHO, Marcus J. M. de. Os índios de Pernambuco no ciclo das insurreições liberais, 1817/1848: ideologias e resistência. Revista da Sociedade Brasileira de Pesquisa Histórica, n. 111, p. 51-69, 1996.

COSTA, F. A. Pereira da. Anais Pernambucanos. Versão em CD encarte de Folk-lore pernambucano: subsídios para a História da poesia popular em Pernambuco. Recife: CEPE, 2004.

LEVI, Giovanni. A herança imaterial: trajetória de um exorcista no Piemonte do século XVII. Rio de Janeiro: Civilização Brasileira, 2000.

MEDEIROS, Ricardo Pinto de. Política indigenista do período pombalino e seus reflexos nas capitanias do norte da América portuguesa. In: OLIVEIRA, João Pacheco de. (org.). A presença indígena no Nordeste: processos de territorialização, modos de reconhecimento e regimes de memória. Rio de Janeiro: Contra Capa, 2011. p. 115-144.

NEVES, Lúcia Maria Bastos Pereira das. Estado e política na independência. In: GRINBERG, Keila. SALLE, Ricardo. 0 Brasil Imperial, volume 1: 1808-1831. Rio de Janeiro: Civilização Brasileira, 2009. p. 95-136.

OLIVEIRA, João Pacheco de. (Org.). 0 Nascimento do Brasil e outros ensaios: "pacificação", regime tutelar e formação de alteridades. Rio de Janeiro: Contra Capa, 2016.

PEIXOTO, José Adelson Lopes. Memórias e imagens em confronto: os Xukuru-kariri nos acervos de Luiz Torres e Lenoir Tibiriçá. Dissertação de mestrado em Antropologia/UFPB, 2013. 
REVEL, Jacques. Jogos de escala: a experiência da microanálise. Rio de Janeiro: Editora da FGV, 1998.

SAMPAI0, Patrícia. Política indigenista no Brasil imperial. In: GRINBERG, Keila. SALLES, Ricardo (orgs.). 0 Brasil Imperial, volume I: 1808-1831. Rio de Janeiro: Civilização Brasileira, 2009. p. 175-206.

WEBER, Marx. Relações comunitárias étnicas. In: WEBER, Marx. Economia e sociedade: fundamentos da sociologia compreensiva. Brasília: Editora da Universidade de Brasília, 2009. p. 267-277.

Recebido em 21 de janeiro de 2020. Aprovado em 11 de maio de 2020. 